\title{
UN PASADO PARA EL FUTURO. SARMIENTO EN MANUEL ROJAS
}

\author{
Alejandro Fielbaum $S$. \\ Université Paris 8 \\ París, Francia \\ afielbaums@gmail.com
}

\section{RESUMEN/ABSTRACT}

Tras introducir algunas posiciones en los debates críticos del canon y la historiografía literaria, se presenta la concepción política de la literatura en Manuel Rojas y la lectura que su perspectiva abre acerca de Domingo Faustino Sarmiento. Ella contrasta con la imagen de Sarmiento construida por la historiografía literaria chilena conservadora, que cuestiona sus excesos, en contraposición con la moderación de Bello. Rojas apunta que Sarmiento habría sido un autor no tan impetuoso, capaz de desplegar una "mesura desmesurada", la que le permite polemizar con libertad. Su posición resulta entonces necesaria para abrir la libertad literaria en Chile, que Rojas quiere rescatar para su siglo.

Palabras clave: Manuel Rojas, Domingo Faustino Sarmiento, Andrés Bello, historiografía literaria, canon.

\section{A PASt For the Future. Sarmiento in Manuel Rojas}

After the introduction of some positions in the critical debates of the canon and literary historiography, we present the political conception of literature in Manuel Rojas and the reading that his perspective opens about Domingo Faustino Sarmiento. Rojas's reading contrasts with the image of Sarmiento constructed by conservative Chilean literary historiography, which questions his excesses, as opposed to Bello's moderation. Rojas points out that Sarmiento was an author not so impetuous, capable of displaying an "immoderate moderation", which allows him to polemicize freely. Sarmiento's position was necessary to open the literary freedom in Chile, which Rojas wants to rescue for his century. 
KEYWords: Manuel Rojas, Domingo Faustino Sarmiento, Andrés Bello literary historiography, canon.

Recepción: 24/11/2020

Aprobación: 23/12/2020

Todo aquello, sin embargo, no fue en vano: aquí está la esperanza, rebrotando con una fuerza que produce miedo, con una fuerza que está casi más allá de nuestra capacidad de soportarla. Es triste, claro está, muy triste que una esperanza se nutra de hombres muertos, de ciudades rendidas o destrozadas, de incendios, de sangre y de exterminio, pero no siempre le es dado al hombre elegir la materia con que se nutrirá su esperanza.

(Rojas, "De qué se nutre la esperanza" 202)

\section{UNA HERENCIA INSOSPECHADA}

Para una mirada apresurada, las posiciones de Domingo Faustino Sarmiento ante la política y la literatura parecen incompatibles con las de Manuel Rojas: El explícito racismo que atraviesa el programa liberal del primero poco se relaciona con la posición del segundo, crítico de la modernización liberal que despliegan los Estados latinoamericanos bajo los liderazgos de Sarmiento y varios de sus continuadores. Sin embargo, las pocas páginas que Rojas dedica a Sarmiento en su Historia de la literatura chilena están marcadas por cierta alabanza, que harto contrasta con las posiciones de la crítica literaria chilena ante Sarmiento. Explicar ese movimiento es el objetivo de este trabajo.

De acuerdo a lo que intentaremos mostrar, lo que Rojas rescata en Sarmiento no son tanto los contenidos de su obra, sino la posición que emplaza con respecto a la lengua, cierto gesto desmesurado que Rojas busca heredar para la política de la literatura para su siglo. Para poder pensar, entre otras cuestiones, una política no racista, pareciera que a Rojas le resultan más productivos los excesos de Sarmiento que las posiciones que parecen menos racistas por ser más mesuradas. Es justamente esa mesura, de acuerdo a Rojas, la que impide cierta transformación en la lectura y la escritura, cierta crítica ante autores como el propio Sarmiento.

Para explicar la estrategia de lectura de Rojas, deberemos dar cierto rodeo en las discusiones sobre el canon en literatura y el establecimiento del canon 
literario en Chile, renuente a la figura de Sarmiento. Tras ello, presentaremos algunas de las ideas con las que Rojas lee el rol de la crítica y la escritura literaria. Con ellas intentaremos, sobre el final, explicar lo que se juega en las breves y condensadas páginas que dedica a Sarmiento.

\section{CANON Y GUERRILLA}

En su señero Sur Racine, Barthes cuestiona que los entonces recientes acercamientos entre la literatura y otras disciplinas no habían desplazado la noción del autor (143). Analogada al concepto de acontecimiento en la historiografía tradicional, Barthes clama entonces por otra historiografía literaria -si es que no, una historia de las obras literarias que ya no fuera de la literatura, como la propuesta poco antes por Escarpit (1800)- que pudiera desplazar esa noción, como luego han contribuido a hacerlo, y de manera tan decisiva, varios de sus trabajos.

A partir de esa y otras críticas a las categorías tradicionales de la historiografía literaria tradicional, en los años setenta y ochenta la crítica literaria latinoamericana comienza a revisar y cuestionar los relatos dominantes de la literatura de cada país, o del continente, de acuerdo con lo que recuerda Pratt (72). Un ejemplo ya clásico de esa crítica puede leerse en el trabajo de González Stephan, quien explicita que la configuración de la historiografía literaria en Latinoamérica corresponde a un constructo histórico que expresa la mirada de los grupos dominantes que buscan construir su pasado cultural $(20)^{1}$. Ese gesto se ha prolongado hasta el presente, la crítica a los criterios implícitos de toda canonización parece ya una posición establecida desde la cual indagar en el tema (por ejemplo, Valdez 207).

Por lo mismo, hoy parece imposible suponer cierta neutralidad a la hora de establecer cierto relato de la historia literaria, en Latinoamérica y también

\footnotetext{
No está de más explicitar que los relatos entonces objetados estaban lejos de asegurar la existencia de cierta historiografía literaria que efectivamente otorgase una versión del canon. De acuerdo con Françoise Perus, las historiografías literarias en Latinoamérica han formado parte de las tentativas de consolidación de Estados nacionales que, por sus debilidades institucionales y por las brechas entre distintos sectores de la población, no han logrado construir una representación literaria de la nación efectiva para la mayor parte de la población (61-62).
} 
en otros espacios. En esa dirección, Alain Vaillant afirma que en el combate por los valores literarios pueden aparecer historias literarias de izquierda y de derecha (42). Evidentemente, ello no se reduce al énfasis que pueda haber en la inclusión o exclusión de obras vinculadas a la izquierda o a la derecha. Antes bien, se trata de una disputa por lo que pueda considerarse o no como literatura, y por quiénes, por qué y cómo allí se incluyen.

Contra la tentación de un posible relato unitario, de un nuevo canon de izquierda, Idelber Avelar sugiere en este debate lo que denomina, con comillas, una "táctica de guerrilla". Las comillas parecen deberse a la irreductible diferencia entre el combate militar y el literario, a la vez que la similitud táctica parece explicarse por la guerrilla como un momento de resistencia que no establece un nuevo poder centralizado desde el cual, en este caso, administrar el pasado literario. Antes que un nuevo canon, Avelar apuesta por minar unos u otros criterios con los que se establece un canon.

El crítico brasilero reconoce el carácter modesto y localista de su propuesta, dada su desconfianza de cualquier valor literario que se crea universal. Sin embargo, quizás es ello lo que abre la posibilidad de un trabajo mucho más intenso que aquel que pudiera conformarse al alcanzar algún criterio o canon:

[E]l más absoluto valor estético debe ser aquél que nos permita, a cada momento, desarmar completamente los absolutos y volver a rearmarlos, permitiéndonos vislumbrar algo obnubilado en los arreglos anteriores. Lo que quizás no sea, al fin y al cabo, un programa tan modesto para la literatura, en una época en que la doxa política y periodística reinstala la creencia en universales cuyos compromisos y complicidades particulares quedan, tan a menudo, más que visibles (221).

\section{DESNACIONALIZACIONES DE LA HISTORIA LITERARIA}

La propuesta de Avelar parece lúcida en tiempos en que a las doxas descritas se suman pulsiones académicas por elaborar antologías y relatos que pudieran brindar nuevos relatos, críticos de los antiguos relatos, del canon por estudiar. Sean historias literarias o culturales, nacionales o continentales, la disputa por el canon parece hoy estar más cerca de la elaboración de nuevos cánones, que puedan asumir su carácter contingente, que de la renuncia a los relatos que sinteticen una u otra tradición literaria. 
Puede que el país que haya acusado más directamente ese desafío sea Argentina. Después de la destacable serie de volúmenes sobre la literatura de aquel pais dirigida por Noé Jitrik, en los que pueden leerse variados artículos que desafían los límites de las consideraciones tradicionales de la literatura y su organización por géneros y autores, han aparecido compilaciones que ya desde sus títulos disputan los supuestos con los cuales narrar una historia nacional de la literatura, ora por reconocer la existencia de más de una historia, ora por desplazar la consideración nacional de la literatura. En concreto, pensamos en la Historia feminista de la literatura argentina o el también ambicioso proyecto de la Historia comparada de las literaturas argentina y brasileña. Mientras la primera, dirigida por Nora Domínguez, Laura Arnés y María José Punte, tendrá seis tomos, la segunda, a cargo de Marcela Croce, ha publicado ya seis.

Los más modestos desarrollos de la historiografía literaria chilena no cuentan con proyectos tan ambiciosos, en parte por la inexistencia de un relato respetado de la historia de la literatura chilena que pueda luego ser suplementado por otros abordajes. El saludable proyecto de una Historia crítica de la literatura chilena coordinado por Grínor Rojo y Carol Arcos promete dar ese relato, validado con criterios más actualizados de la crítica literaria. Las secciones de los dos tomos ya publicados no son del todo autorales, ni carecen de preocupación por temas emergentes en la crítica. Con ello, el proyecto aspira a la construcción de un nuevo relato de la literatura chilena. En su presentación, propone una enérgica reformulación del canon (Rojo y Arcos 12).

En el marco de tales discusiones, nos parece necesario revisar críticamente las previas estrategias de construcción del canon que se cuestiona. La obra de Rojas resulta allí de interés dado que es un autor que podría considerarse parte del canon de la tradición narrativa que elabora su propia versión del canon. Si todo escritor lee inventando sus tradiciones a partir de una guerra en las lecturas, como lo explicita Piglia (24), una lectura de las batallas de Rojas puede ayudar a pensar en cierta crítica de los relatos canónicos de la literatura nacional. Y quizás un buen paso para intentar historizar esa noción, a propósito de los debates sobre lo que seguimos llamando literatura chilena, pueda ser el análisis de cierta ficción del origen en la crítica literaria chilena. 


\section{DE ÓRDENES Y RAPTOS}

Si bien desde el proceso de Independencia se dan discusiones acerca de la relación entre la escritura literaria y la emergente república ${ }^{2}$, es recién en los debates que en 1842 se articulan en torno al romanticismo que pueden leerse posiciones colectivas con respecto a la crítica literaria y su porvenir. Como puede leerse en el volumen compilado por Ana Figueroa, combate allí cierta posición que aspira a construir una nueva lengua literaria en español con otra que defiende una lengua más respetuosa de la herencia española. Las figuras más recordadas de uno y otro bando son Domingo Faustino Sarmiento y Andrés Bello, respectivamente. Antes que indagar acá en sus textos, nos interesa resaltar las lecturas del debate porque ellas habilitan distintos relatos acerca del origen del espacio literario chileno, y con ello sobre la misión que lega al futuro. En particular, con respecto al rol que allí le viene a la crítica, a los modos de validar la literatura en la emergente república.

Evidentemente, no podría haber una lectura simple del origen de la crítica chilena donde y cuando se trata de un debate en el que destacan un venezolano y varios argentinos, varios de los cuales firman con seudónimos los textos de prensa, que oscilan entre el panfleto, la fábula, la crítica y la teoría. Como bien describe Flórez (50 y ss.), los términos y criterios mismos de inclusión de autores son objeto de disputa por parte de relatos que se siguen brindando de la polémica. La mayoría de ellos destacan el profundo legado de Bello por sobre la irrupción de Sarmiento, considerada ocasional, algo infecunda ${ }^{3}$.

2 Por ejemplo, José Joaquín de Mora y Andrés Bello arriban a Chile ya habiendo escrito importantes textos acerca de la literatura. Mientras el primero anima la así llama querella calderoniana en España, el segundo había ya realizado una primera versión de su estudio sobre el Cid. En Chile, por cierto, su preocupación por tales temas no cesa. Sin embargo, la conocida polémica que enfrenta los bandos liderados por uno y otro ( $c f$. De Ávila) está lejos de dar a la literatura la centralidad que tendrá en los debates del 42.

No está de más señalar que algunas de las críticas a Sarmiento, y a otros de sus aliados, insisten en su carácter extranjero. Es como si se le reprochase la instalación del desorden en el orden cuya hospitalidad debieran agradecer en la omisión de cualquier cuestionamiento. Ya en una de las réplicas de Minvielle a Sarmiento a propósito de la ortografía puede leerse ese reproche: "No concluiré esta carta, escrita con toda la amargura de que se halla poseído mi corazón, sin recordar a Ud. cuál era su posición y la de todos sus desgraciados compañeros hace dos años y cuál es ahora. Entonces todos eran compadecidos y aun estimados; ahora son mirados en general como unos Parias. Esta metamorfosis la atribuyen todos, hasta los que son sus inocentes víctimas, al carácter impetuoso de unos pocos, al desenfado con que siempre 
Esta posición puede ya leerse en la obra de Raúl Silva Castro, obra que por cierto Rojas recuerda haber citado en su Historia de la literatura chilena, aun cuando se disculpa por haberlo olvidado a la hora de referir a la historia de la crítica literaria en Chile ("Recuerdos de Raúl Silva Castro" 258). Como cualquier olvido, el de Rojas resulta sintomático. Y es que la posición de Silva Castro resulta bastante conservadora ante la escena que nos interesa revisar.

En su Panorama literario de Chile publicado en 1961, Silva Castro emplaza la obra de Sarmiento dentro de la literatura de costumbres (438) -el ensayo en Chile emerge, según sostiene, con Sociabilidad chilena, de Francisco Bilbao (451)-. Considerando que el Facundo fue escrito en Chile, aunque no como un volumen unitario, podemos sospechar que en esa caracterización aparezca cierto desdén a propósito de la obra de Sarmiento. Lo que sí es seguro es que en otros pasajes Silva Castro reprocha la personalidad de Sarmiento, la que habría obstruido la claridad de su escritura. Así, a propósito del 42, Silva Castro destaca que Sarmiento olvida que él mismo habría comenzado la polémica al publicar un texto de poco interés, tras lo cual el argentino habría estallado en uno de esos raptos homéricos que caracterizaban su genio (525).

A Sarmiento, entonces, se le reconoce un ímpetu genial que ni él mismo podría administrar. Dada la posición romántica que se le suele seguir atribuyendo, se supone en Sarmiento cierto desorden. De ahí que el crítico del siglo XX pueda sostener que el escritor de costumbres del XIX carecía de discernimiento y finura, al punto que su talento habría sido el de barajar golpes e injuriar. Sarmiento, de este modo, es presentado como quien prefiere discutir más que aclarar, al punto que Silva Castro apunta que quizás la polémica del 42 mejora paulatinamente cuando Sarmiento se retira de ella.

Pareciera que entonces la defensa de Bello de cierto orden en las letras correspondiese con una posición más ordenada en el debate: Bello se mantiene en el debate con directrices claras, las que legan una posición clara. A diferencia de los inconexos brotes de genialidad de Sarmiento, Silva Castro destaca que

emiten estos sus opiniones, al desprecio con que miran a todo el mundo, desprecio que se ve en todos sus escritos, en todos sus actos, hasta en la sonrisa que alguna vez asoma en sus labios. Y no basta [a] rehabilitarlos en la opinión, la honradez y la cordura con que los más se conducen en la sociedad. Verdad es este tan innegable que puede decir a Ud. sin miedo de ser desmentido que algunos, muy pocos es verdad, de los argentinos, entre ellos Ud., se han acarreado tanta dosis de aversión y odio como todos los españoles juntos en tiempo en que la guerra con España estaba en todo su vigor" (cit. en Contreras 40, con leves modificaciones para modernizar la ortografía). 
Bello lega una obra que permite que la cultura chilena se desarrolle gracias a sus directrices, pese a los deseos de Sarmiento.

\section{UNA ESTATUA CONTRA LA PESTE}

Ese tipo de loas al rol fundacional de Bello en la cultura chilena es reiterada hasta el presente ${ }^{4}$. Con ello se defiende tanto su obra literaria como su aporte en las instituciones jurídicas y políticas. En su Historia personal de la literatura chilena, en efecto, Alone señala que Bello completa y perfecciona la obra de Portales, a la vez que parece sentar las bases de una literatura que sin él no podría haber germinado. Mientras Sarmiento es descrito como un hombre de fuerza bravía y libertaria, una confusión genial, desmelenada, violenta (Historia personal de la literatura chilena 138), la mesura de Bello parece menos genial y violenta. Y, por lo mismo, más fecunda.

Al no ser unilateral, la obra de Bello abre la posibilidad de distintos recorridos, como podría recordarlo quien recordase las distintas derivas de algunos de sus estudiantes. El rector abre la posibilidad de la literatura que otros recorrerán. La obra de Bello estaría tan enrevesada en las raíces de la cultura chilena, según Alone, que nada se entendería de ella si Bello faltara (Historia personal de la literatura chilena 145).

La defensa de Bello deviene entonces la defensa de Chile, y viceversa, ante lo que Alone y la derecha perciben como la amenaza del corte con la raíz que traerían ideas que el conservadurismo tilda de extranjeras. En particular, cuando los confundidos contra los que quiere discutir Alone no son los del siglo XIX. Si en 1972 Alone describía a Bello como un civilizador cuya obra habría que rescatar de su posibilidad de transformarse en ruina (En la batalla política 36), en noviembre de 1973 celebra ese rescate gracias al Golpe de Estado que, para Alone, restituye el orden que habría gestado Bello y que el marxismo casi arruina definitivamente. La elocuencia de Alone resulta tan sincera y violenta que obliga a una larga cita:

A modo de ejemplo, pueden revisarse las presentaciones leídas en el Centro de Estudios Públicos realizadas a partir del lanzamiento del destacado libro de Joaquín Trujillo sobre Bello. La sesión puede verse en https:/www.youtube.com/watch?v=8WGXIvFWULc 
Una peste se había extendido por el país, una especie de epidemia cubría de lepra los muros de la ciudad, las paredes de los caminos, se propagaba inconteniblemente por los barrios y envolvía incluso el pedestal de su monumento, con los peores atentados contra la Gramática, el léxico y el uso de "la gente bien educada". El país sufría estupefacto e impotente esta invasión primitiva en el seno de la civilización. Ciertos diarios eran "cloacas ambulantes". Se había perdido el respeto a todo: los insultos encarnecían la moral pública; calumnias con nombre personal afrentaban a los magistrados máximos, se mofaban de instituciones fundamentales, corroían el pudor de la juventud y hacían irrespirable la atmósfera a los hombres maduros (En la batalla política 391-392).

Contra la momentánea disolución del orden, el Golpe de Estado impone la mescolanza entre orden y autoridad que lega Bello. Su estatua en la Universidad ha sido la principal vencedora del 11 de septiembre, escribe ridículamente Alone, quien además apunta que con el Golpe la decencia y el orden borran mágicamente el desorden, retomando la posibilidad de una discusión letrada que respeta las jerarquías que Alone naturaliza. Recién entonces parece posible que Bello siga humanizando a Chile, con la letra que aún vigila y protege contra las asechanzas, el desbordamiento y el caos (Alone, En la batalla política 393).

No es difícil notar aquí las implicaciones políticas de esta elaboración de la historia literaria nacional, en la cual se erige a Bello como una figura asociada al orden, en contraposición a la de Sarmiento. Si bien Alone, al igual que Silva Castro, están lejos de culpar a Sarmiento por los embates marxistas contra el orden, al tomar partido por Bello toman partido por cierta crítica que contenga sus propios excesos y así colabore con la edificación, y no con la supuesta destrucción, del orden social.

La celebrada lectura de Andrés Bello realizada por Iván Jaksic muestra la continuidad de este esquema, vinculado ahora a otra defensa, ya no pinochetista, del orden. Después de la dictadura, Bello ya no se lee como un crítico de la Unidad Popular, sino como un defensor de la mesura concertacionista. La superioridad de Bello sería tal que solo con su virtud podría notarse el valor de la ambivalente personalidad de Sarmiento, hombre atolondrado pero (y no, como sería más interesante, por ello) buen educador. Coherente con el discurso de los consensos, Bello es capaz de acercar posiciones, tomando sus virtudes contra los excesos que la acompañan: 
Sarmiento era también una persona combativa, arrogante y quisquillosa que se trenzaba en polémicas que terminaba exasperando a sus propios partidarios y que fueron minando su credibilidad. Se requería la enorme paciencia de hombres como Montt y Bello para cultivar los aspectos positivos antes que concentrarse en los negativos de la personalidad del sanjuanino (Jaksic 195).

Un último ejemplo de esta contraposición puede hallarse en un texto de menor ambición académica, y por lo mismo sintomático del carácter extendido de la forma binaria con la que se sigue comparando a Bello y Sarmiento. Se trata de un breve ensayo de Rafael Gumucio, quien reconoce la importancia de ambos autores, los que describe retomando las imágenes ya presentadas: Bello sería dulce y pedagógico, Sarmiento testarudo y ególatra; Bello un maestro pausado, Sarmiento un panfletario en llamas cuya única lección sería el fuego. Por lo mismo, Bello legaría una literatura muerta, Sarmiento una creación viva: Bello un país, Sarmiento un estilo.

De acuerdo a Gumucio, Chile se identifica con Bello y Gumucio, deseoso de ser un escritor, con Sarmiento. No es aquí el lugar para discutir si lo logra. Simplemente, nos interesa concluir esta sección remarcando que al invertir la valoración entre ambos autores termina confirmando el supuesto político a la base de tales lecturas revisadas: es imposible fundar un legado con Sarmiento, salvo quizá para la literatura como esfuerzo individual que Gumucio piensa al margen, si es que no contra, cualquier idea de la política5 ${ }^{5}$.

\section{MANUEL ROJAS: TRABAJO, LITERATURA Y COMPROMISO}

Para pensar la posibilidad de un orden que no piense sus críticas y transformaciones como imposibilidad del orden, resulta necesario pensar de otra manera la

\footnotetext{
No está de más apuntar que estas miradas a Sarmiento contrastan con las lecturas realizadas en Argentina a lo largo del siglo XX. Evidentemente, acá no podemos dar cuenta de ellas, de modo que nos limitamos a mencionar los textos que dedican a esta cuestión Sarlo y Sorensen, y a recordar que Borges destaca el entusiasmo de Sarmiento como posible clave de otra modernización posible, menos conservadora en términos literarios (69). Es decidor acerca del carácter conservador de la tradición crítica chilena el hecho de que la posición de Borges, a quien difícilmente podría considerarse un abogado de la desmesura, parezca algo radical si se la contrasta con la mirada de la crítica chilena hegemónica a la obra de Sarmiento.
} 
literatura y la política. Esa posición puede leerse en los ensayos de Manuel Rojas, particularmente en los compilados en el volumen De la poesía a la revolución. Como ya lo indica el título, la posición de Rojas busca pensar el paso de la literatura a la política. Contra lo que se podría sospechar en el título, para Rojas no se trata de un paso lineal ni unívoco. Antes bien, Rojas asume que para pensar ese quiasmo de modo revolucionario resulta necesario pensar la literatura como una forma crítica de posicionamiento que no ha de perderse en la acción política.

Parafraseando a Víctor Jara, para Rojas el hombre es un creador. Habría que ponderar, por cierto, los límites androcéntricos del enunciado. Lo interesante es que, al menos en el caso de Rojas, esa posición humanista puede abrir, más allá de su obra, cierta línea ligeramente antihumanista, puesto que abre la crítica a toda idea de un sujeto constituido antes de sus relaciones materiales con otros elementos materiales ${ }^{6}$.

Las interacciones entre sujetos y objetos permiten el despliegue de lo que Rojas llama cultura, esto es, el dominio de elementos materiales y mentales que permiten el despliegue de la lucha contra la oposición inerte del mundo. En esas dinámicas, Rojas sitúa tanto el trabajo del obrero como el del artista. Ambas forman parte de la transformación humana del mundo. En una eventual sociedad no alienada, ambas formarían parte de lo que concibe como un producto del espíritu. Una adecuada concepción del trabajo piensa entonces el trabajo manual como parte del trabajo intelectual, a la vez que instala la posición del escritor dentro de la producción material de la vida.

Contra la separación de la estética moderna entre creación y reproducción, para Rojas la literatura no ha de comprenderse en la esfera espiritual del genio, sino en los procesos materiales de producción de la vida. La naturalizada separación entre arte y trabajo, a partir de la que buena parte de la crítica humanista cuestiona el orden capitalista, es para Rojas un supuesto del orden capitalista que se quiere criticar. Al humanismo conservador no se le combate con un humanismo con contenidos de izquierda, sino con la política que interrogue la separación humanista entre economía y espíritu, propia de la división social capitalista del trabajo, productora de miseria en la economía

6 Pensamos, predeciblemente, en la posibilidad de leer algunas posiciones de Rojas con ciertos desarrollos de la filosofía contemporánea que han intentado reunir los nombres de Spinoza, Marx y Simondon, entre otros. Véase al respecto, por ejemplo, Balibar. 
y en el supuesto espíritu. De ahí la necesidad de otro modo de producción de la vida, capaz de reunir trabajo material e intelectual:

Si el proletariado supiera que no trabaja ya para el patrón, para un grupo o para una clase, sino para la colectividad, y que esta colectividad, de la que forma parte, está empeñada en construir, por ejemplo un sistema social y económico más elevado que el actual, el trabajo ya no sería para él una carga: tendría algún sentido no puramente material, y por ese sentido se escaparía, transformado, aquel que siente en sí y que no puede desarrollar: el de creación. Crearía, en otra forma, pero crearía (De la poesía a la revolución 166).

Para ponerse al servicio de esas transformaciones, la literatura debe sustraerse del aislamiento en que la sitúa el orden capitalista. Ello no supone dejar de escribir, sino hacerlo de otra forma. En lugar de insistir en la literatura como una inspiración genial individual, ha de nutrir y nutrirse de otras prácticas. Rojas, en efecto, cuestiona a los escritores chilenos que su cultura sea meramente literaria, ignorante de las discusiones biológicas, psicológicas o filosóficas en boga. Para salir del criollismo que Rojas critica tan duramente, resulta necesaria otra relación con el paisaje ensalzado por los criollistas. A saber, la que pueda valerse de los distintos saberes y prácticas que transforman esos paisajes naturales en paisajes culturales con la ayuda de los paisajes sensibles que inventa la literatura ("Algo sobre mi experiencia literaria" 37), que forma parte de esas transformaciones.

Rojas aspira a forjar esa nueva alianza entre saberes y sentires. Posibilitada por un conocimiento creativo de los nuevos saberes, ha de sugerir e iluminar nuevas creaciones (De la poesía a la revolución 68). La tarea del escritor, en ese marco, no es la de representar una experiencia colectiva ya existente, sino la de crear nuevos modos de vida colectiva en la lengua, irreductibles a unos u otros límites o saberes. En diálogo con otros saberes y experiencias, la literatura ha de eludir límites disciplinares y geográficos. En efecto, Rojas explicita que su literatura tiene un sentido universalista ("Lo que la vida me ha hecho sentir" 32).

De ahí que la responsabilidad del escritor no pase por un pueblo o partido en particular. Ante el bullado y necesario debate sobre el compromiso político del escritor, Rojas considera que el posicionamiento del escritor no se juega en el vínculo orgánico con alguna forma de creación ya dada, sino por su infinita vigilancia ante el orden existente, sus instituciones y espacios: 
no veo para el escritor honrado porvenir espiritual alguno en la política militante, aunque sí lo veo en una actitud política independiente. En mi concepto, mientras los partidos que persiguen el poder o que ya están en él, no le ofrezcan un clima moral indispensable para poder subsistir como individuo libre de intereses de clase o económicos, el escritor deberá dedicarse a defender los puntos que he indicado. Ese es, por ahora, según mi juicio, la única actitud política posible para él (De la poesía a la revolución 173).

\section{LEER CON LA CRÍTICA}

De este modo, Rojas considera la literatura dentro de la historia de la creación humana de la que debe desprenderse críticamente. Tan torpe sería el escritor que se piense al margen de la historia como el que, por asumirse en ella, no imaginase otros modos de habitarla, no criticase los distintos poderes instituidos. Ese gesto abre la posibilidad de literaturas diversas, eventualmente contradictorias, y acaso el rol de la crítica sea leer con independencia la emergencia de posiciones independientes para abrir futuras independencias que ya no se piensen desde la independencia política estatal.

Nos parece que es con esos supuestos que Rojas brinda, en el marco de los fructíferos debates sobre cultura y política de los años sesenta, su lectura de la literatura nacional en su Historia breve de la literatura chilena. Se trata de un poco estudiado volumen de casi doscientas páginas elaborado a partir de los materiales de un curso que realiza en la UNAM en 1964, en el que se presenta de manera algo esquemática, la producción literaria nacional. Dividido en cinco periodos subdivididos por género, presenta entradas breves sobre diversos autores. Por ejemplo, la de Mistral cuenta de una página, la de Neruda de tres, a la vez que brinda más espacio a algunos prosistas, incluyéndose a sí mismo.

Pese a la aparente simplicidad que impone ese modelo de libro, puede allí leerse su distancia ante posiciones como las de Silva Castro o Alone. En efecto, Rojas agradece que este último haya pasado de destacar la prosa de Hijo de Ladrón a enfatizar la superioridad de Lafourcade (Historia breve de la literatura chilena, 158). Y es que si bien Rojas reproduce algunas opiniones de Alone a propósito de distintos autores, no parece valorar del todo la entonces celebrada prosa del crítico. Lo considera el principal crítico del país, junto a Latcham, pero puede que ello muestre el descontento de 
Rojas ante la crítica y no una genuina valoración de Alone. Grínor Rojo, en efecto, subraya el deseo de Rojas por el arribo de la inexistente crítica que pueda superar la oposición entre la ignorancia pública y el formalismo académico (11).

Demasiado cómodo en su prédica, Alone no es capaz de forjar esa síntesis. De su prolífica escritura, Rojas solo rescata la Historia personal de la literatura chilena, para luego recalcar la superficialidad de la crítica dominguera. Aun cuando se le deban muchos estímulos (Historia breve de la literatura chilena 192), pareciera no lograr una crítica literaria que pueda sobrepasar las impresiones aristocráticas de quien las enuncia.

\section{LA SINGULAR MESURA DE SARMIENTO}

Contra ese tipo de lecturas, Rojas instala las distintas obras en las tensiones y preguntas propias de cada momento. Durante la Independencia, parece imposible preguntarse por la literatura, puesto que parte del legado colonial es la ausencia de esa posible discusión. Es en el segundo capítulo del libro que Rojas brinda su posición al respecto, justamente alrededor de las obras en las que percibe la emergencia de ese debate, la que arriba con autores extranjeros. Es como si solo la emergencia de la literatura posterior a la descolonización política, y la respectiva apertura a otros saberes, pudiese abrir la pregunta por el rol de las letras para otro tipo de descolonización, capaz de abrir otro tipo de literatura que pueda expresar la singular lengua que emerge con la nueva colectividad:

Una literatura universal, idéntica en todos los países, habría sido y sería tan mala como una pretendida ciencia nacional y no habría producido la variedad y riqueza que le conocemos. Y es que la literatura, con ser también, como producto humano, abstracta y unipersonal o individual, tiene sus raíces y fuente en terrenos diferentes de los que tiene la ciencia... El pensamiento puede existir sin un pueblo; la literatura no, por lo menos la literatura de un pueblo... Es cierto que, a fin de cuentas, la literatura de cada pueblo o cada nación va a dar, como el pensamiento científico, al fondo común de los valores universales, pero el valor universal de la literatura reside precisamente en la personalidad y variedad que aporta cada pueblo (Historia breve... 27) 
Una posible literatura chilena pasa entonces por la invención de una literatura desde Chile, sin que sea necesario que quienes la firmen hayan nacido o no en el país. Es allí donde Rojas destaca la presencia de José Joaquín de Mora, Bello y Sarmiento. Que sean extranjeros quienes otorguen los primeros pasos en la constitución de la literatura chilena no es una paradoja, sino un síntoma de la imposibilidad de cualquier localidad de pensarse al margen de la historia cosmopolita de la literatura, sus tensiones y traducciones. Hermosos tiempos, destaca Rojas, en los que un venezolano podía ser rector de la Universidad de Chile, antes de que el nacionalismo apareciese en Hispanoamérica (Historia breve... 38).

Junto con ello, Rojas destaca la presencia de Bello en ámbitos jurídicos, gramáticos y literarios, enfatizando el respeto que incluso le habrían tenido sus detractores, como Sarmiento. Ese reconocimiento ya desarma el esquema en el que solo Bello es capaz de leer a su interlocutor. La pasión de Sarmiento parece entonces productiva.

En efecto, Rojas subraya su afán por romper con las reglas literarias heredadas de la tradición española, de abrazar la literatura extranjera con énfasis en la cultura francesa y de asumir la educación como patrimonio del pueblo. Tan incesante como Bello, Sarmiento expande su posición por toda discusión en la que se lo encuentre, contraviniendo los distintos límites y autoridades que Bello respeta: “....arremetiendo contra todos los prejuicios, los literarios y los sociales, los gramaticales y los políticos, tocando de lado los religiosos; nada se le escapó y a todo dirigió su mirada, su juicio, su crítica o su alabanza. Le contestan y replica, vuelven a contestarle y vuelve a replicar, sin cansancio y sin demora" (Historia breve... 40).

Es gracias a ese entusiasmo que Sarmiento lega una obra que Rojas considera más vigente que la de Bello, al punto de describir Facundo como un libro inmortal. Que Sarmiento no haya logrado imponer una posición delimitada para su tiempo, capaz de ser continuada, como le critica Alone, es quizás lo que permite que su escritura subsista más allá de la limitada esfera letrada de mediados del XIX, que solo puede ser rescatada después de su presente.

De este modo, al comenzar su exposición sobre la poesía chilena en el siglo XX, Rojas retoma la descripción de Alone de la disputa entre Bello y Sarmiento como un enfrentamiento entre mesura y desmesura, entre razón e imaginación. Triunfa Bello, reconoce Alone, y eso explica un siglo en el que se ausenta la poesía: la mesura impedía la gracia y la originalidad (Historia breve... 101). 
Frente a lo defendido por la crítica conservadora y la progresista, los excesos de Sarmiento resultan necesarios para quien asume que no hay literatura sin exceso, sin la libertad que ha de tomarse el escritor contra los modos establecidos de la lengua permitidos por el orden conservador. Contra la defensa de Bello que quiere retomar su posición ante los desbordes políticos y literarios, Rojas recuerda que incluso en los espacios vencedores el tiempo ha terminado por destacar al entonces vencido:

Si un profesor lee, en una universidad norteamericana, la Oda a la Agricultura de la Zona Tórrida, de Bello, advertirá, si es observador, que los alumnos tienen una expresión de profundo aburrimiento, cosa que no ocurre cuando se les lee algún capítulo de Facundo o de Recuerdos de Provincia. La mesura y lo desmesurado. Por suerte a fines de siglo se logró ahuyentar un poco la mesura. Y entonces empezó a haber poetas, es cierto que algunos demasiado desmesurados, pero otros desmesurados exactamente. Porque también hay una desmesura mesurada (Historia breve... 102).

Esa desmesura mesurada abre así la necesidad de cierta experimentación literaria, de la apertura a una creación sin una regla externa que pueda delimitar cómo mesurarse. Para ello, la lección de Sarmiento parece brindar a Rojas cierta posición de la literatura que sobrepasa los conservadurismos de uno y otro siglo. A saber, la necesidad de que la mesura de la intervención política y literaria no venga delimitada de antemano, que sea la propia experiencia la que pueda elaborarla en sus tanteos ${ }^{7}$. En la carencia de norma que abre la desmesura que promete lo imposible, ha de escribirse sin petición de algún orden pasado. Sin ese gesto, no parece posible abrir otro futuro -de la literatura. Esa lección que Rojas rescata para el siglo XX quizás sea aún más urgente hoy, cuando no hay certeza de que los vencidos vayan a transformarse en vencedores.

7 Evidentemente, un análisis más acabado de esta cuestión habría de ver en qué medida Rojas reescribe ciertas posiciones de Sarmiento. Pensamos, por ejemplo, en el relato cordillerano del cuento "Laguna", que abre la obra de Rojas, y los relatos en los que Sarmiento narra los cruces de la cordillera. 


\section{BIBLIOGRAFÍA}

Alone. Historia personal de la literatura chilena (Desde Don Alonso de Ercilla hasta Pablo Neruda). Santiago: Zig-Zag, 1954.

En la batalla politica. Santiago: Editorial Gabriela Mistral, 1974.

Avelar, Idelber. "La construcción del canon y la cuestión del valor literario". Aisthesis 46 (2009): 213-221.

De Ávila, Alamiro. Mora y Bello en Chile, 1829-1831. Santiago: Universidad de Chile, 1982.

Balibar, Étienne. "De la antropología filosófica a la ontología social y viceversa: ¿Qué hacer con la sexta tesis sobre Feuerbach?”. Trad. Claudio Aguayo. Demarcaciones (2016): 185-207.

Barthes, Roland. Sur Racine. París: Seuil, 1963.

Borges, Jorge Luis. Textos recobrados. Vol. 3. Barcelona: Emecé, 2002.

Contreras, Lidia. Historia de las ideas ortográficas en Chile. Santiago: Centro de Investigación Barros Arana, 1993.

Escarpit, Robert. "Histoire de l'histoire de la littérature". En Raymond Queneau (Director). Histoire des littératures. III. Littératures francaises, connexes et marginales. París: La Pléiade, 1958. 1737-1800.

Figueroa, Ana. Comp. Ensayistas literarios de 1842. Santiago: USACH, 2000.

Flórez, Teresa. "Revisión crítica de la historiografía literaria chilena". Tesis presentada en la Universidad de Chile para optar al grado de Magíster en Literatura con mención en Teoría Literaria, 2008.

González Stephan, Beatriz. La historiografía literaria del liberalismo latinoamericano del siglo XIX. La Habana: Casa de las Américas, 1987.

Gumucio, Rafael. Historia personal de Chile. Los platos rotos: de Almagro a Bachelet. Santiago: Hueders, 2013.

Jaksic, Iván. Andrés Bello: la pasión por el orden. Santiago: Universitaria, 2001.

Piglia, Ricardo. Las tres vanguardias. Saer, Puig, Walsh. Buenos Aires: Eterna Cadencia, 2016.

Perus, Françoise. “'Todavía tiene sentido la historiografía literaria?”. Anuario del Colegio de Estudios Latinoamericanos 2 (2007): 59-65.

Pratt, Mary Louis. ““No me interrumpas”: las mujeres y el ensayo latinoamericano”. Debate Feminista 21 (2000): 70-88.

Rojas, Manuel. “Algo sobre mi experiencia literaria”. Obras. Madrid: Aguilar, 1973. 3-38. De la poesía a la revolución. Santiago: Ercilla, 1938.

"De qué se nutre la esperanza". Babel 46 (julio-agosto 1948): 201-202. Historia breve de la literatura chilena. Santiago: Zig-Zag, 1965.

"Lo que la vida me ha hecho sentir". Manuel Rojas. Estudios críticos. Comp. Naín Nómez y Emmanuel Tornés. Santiago: Universidad de Santiago, 2005. 31-45.

"Recuerdos de Raúl Silva Castro". Páginas excluidas. Santiago: Universitaria, 1997. 254-259. 
Rojo, Grínor. "Prólogo". Manuel Rojas. De la poesía a la revolución. Santiago: LOM, 2015. 8-14. Rojo, Grínor y Carol Arcos. "Prefacio". Historia crítica de la literatura chilena. Volumen I. La era colonial. Eds. Carol Arcos y Grínor Rojo. Coord. Stephanie Massman. Santiago: LOM, 2017. 11-13.

Sarlo, Beatriz. "Sarmiento en el siglo XX". Historia crítica de la literatura argentina. Volumen 4. Sarmiento. Adriana Amante, Dir. del volumen; Noé Jitrik, Dir. de la obra. Buenos Aires: Emecé, 2012. 367-391.

Sorensen, Diana. El Facundo y la construcción de la cultura argentina. Trad. César Aira. Rosario: Beatriz Viterbo, 1998.

Silva Castro, Raúl. Panorama literario de Chile. Santiago: Universitaria, 1961.

Vaillant, Alain. L'histoire littéraire. París: Armand Colin, 2017.

Valdez, Michael. "Caliban and his precursors: the politics of literary history and the first world". Theoretical Issues in Literary History. Comp. David Perkins. Harvard: Cambridge University Press, 1991. 206-223. 